\title{
Evaluation of the antioxidant effects of different histone deacetylase inhibitors (HDACis) on human lens epithelial cells (HLECs) after UVB exposure
}

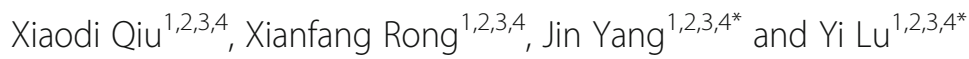

\begin{abstract}
Background: To compare the protective effects of the histone deacetylase inhibitors (HDACis) $\beta$-hydroxybutyrate $(\beta O H B)$, trichostatin $A(T S A)$, suberoylanilide hydroxamic acid (SAHA) and valproic acid (VPA) on human lens epithelial cells(HLECs) following ultraviolet-B (UVB) exposure.

Methods: HLECs were divided into subgroups: four HDACi groups, a control group, a UVB-treated group and a DMSO group (cells treated with DMSO and UVB irradiation). In the HDACi groups, HLECs were cultured with different concentrations of HDACis $12 \mathrm{~h}$ prior to UVB irradiation. The protective effects of the HDACis were evaluated by assessing apoptosis rates, cell activity and expression levels of genes associated with apotosis (caspase-3, BCl-2, BAX, SOD1, FOXO3A and MT2). The levels of superoxide dismutase (SOD), reactive oxygen species (ROS), malondialdehyde (MDA) and total antioxidant capacity (T-AOC) were detected in order to evaluate oxidative stress.

Results: The results showed that SAHA $(1 \mu \mathrm{mol} / \mathrm{L}, 2 \mu \mathrm{mol} / \mathrm{L})$ and TSA $(0.2 \mu \mathrm{mol} / \mathrm{L})$ had mild protective effects on cell viability. $\beta O H B(4 \mathrm{mmol} / \mathrm{L})$ and TSA $(0.2 \mathrm{~mol} / \mathrm{L})$ demonstrated protective effects on $\mathrm{BCL}-2$ expression. TSA $(0.2 \mathrm{~mol} / \mathrm{L})$ showed protective effects on SOD1 expression. TSA ( $0.2 \mathrm{~mol} / \mathrm{L})$ and SAHA (1 $\mu \mathrm{mol} / \mathrm{L})$ suppressed BAX and caspase-3 expression. TSA $(0.2 \mathrm{~mol} / \mathrm{L}, 0.8 \mathrm{~mol} / \mathrm{L})$ and SAHA $(1 \mu \mathrm{mol} / \mathrm{L}, 2 \mu \mathrm{mol} / \mathrm{L})$ suppressed the expression of FOXO3A and MT2. SOD levels were increased after treatment with $\beta O H B(4 \mathrm{mmol} / \mathrm{L})$, SAHA $(8 \mu \mathrm{mol} / \mathrm{L})$ and TSA $(0.1 \mathrm{~mol} / \mathrm{L}, 0.2 \mathrm{~mol} / \mathrm{L})$. T-AOC levels were increased in UVB-treated HLECs after treatment with SAHA ( $2 \mu \mathrm{mol} / \mathrm{L})$. MDA levels decreased in UVB-treated HLECs following treatment with TSA ( $0.2 \mathrm{~mol} / \mathrm{L}, 0.8 \mathrm{~mol} / \mathrm{L})$. ROS levels decreased in UVB-treated HLECS following treatment with $\beta O H B(4 \mathrm{mmol} / \mathrm{L})$, SAHA $(1 \mu \mathrm{mol} / \mathrm{L}, 2 \mu \mathrm{mol} / \mathrm{L})$ and TSA $(0.2 \mathrm{~mol} / \mathrm{L})$. Western blotting results demonstrated that SOD1 levels significantly increased in the $\beta O H B(4 \mathrm{mmol} / \mathrm{L}), \mathrm{SAHA}(1 \mu \mathrm{mol} / \mathrm{L}, 2 \mu \mathrm{mol} / \mathrm{L})$, TSA $(0.1 \mathrm{~mol} / \mathrm{L}, 0.2 \mathrm{~mol} / \mathrm{L})$ and VPA (5 mmol/L) groups. Only SAHA (1 $\mu \mathrm{mol} / \mathrm{L})$ had an anti-apoptotic effect on UVB-treated HLECs.

Conclusions: Our findings indicate that low concentrations of HDACis (1 $\mu \mathrm{mol} / \mathrm{L}$ of SAHA) mildly inhibit oxidative stress, thus protecting HLECs from oxidation. These results may suggest that there is a possibility to explore the clinical applications of HDACis for treatment and prevention of cataracts.
\end{abstract}

Keywords: Histone deacetylase inhibitors, Lens epithelial cells, Ultraviolet-B exposure, Oxidative damage, Beta hydroxybutyrate, Suberoylanilide hydroxamic acid, Trichostatin a, Valproic acid

\footnotetext{
*Correspondence: jin_er76@hotmail.com; luyieent@126.com

'Eye Institute, Eye and Ear, Nose, and Throat Hospital of Fudan University, 83

Fenyang Road, Shanghai 200031, People's Republic of China

Full list of author information is available at the end of the article
}

(c) The Author(s). 2019 Open Access This article is distributed under the terms of the Creative Commons Attribution 4.0 International License (http://creativecommons.org/licenses/by/4.0/), which permits unrestricted use, distribution, and reproduction in any medium, provided you give appropriate credit to the original author(s) and the source, provide a link to the Creative Commons license, and indicate if changes were made. The Creative Commons Public Domain Dedication waiver (http://creativecommons.org/publicdomain/zero/1.0/) applies to the data made available in this article, unless otherwise stated. 


\section{Introduction}

Histone (de)acetylation is the most frequent epigenetic modification and has been shown to exert diverse effects on transcriptional activity, interactions between histones and DNA, changes in chromatin structure and the regulation of nucleosomes [1]. The combined action of histone acetyltransferases (HATs) and histone deacetylases (HDACs) mediate the acetylation state of nucleosomal histones [2]. HDACs condense chromatin and reduce gene expression by removing the acetyl group from histones [3]. There had been several HDAC inhibitors (HDACis) which could block the catalytic activity of HDACs [4].

HDACis had been used in psychiatry and neurology as mood stabilizers and anti-epileptics for a long time [5]. Recently, HDACis have drawn attention for potential application in the treatment of neurodegenerative diseases, cancer and inflammatory diseases [6-8]. A previous study from our group found that the decrease of histone acetylation at the SOD1 promoter is associated with the decrease of SOD1 expression in age-related cataracts. Histone acetylation has an important role in regulating SOD1 expression which participate in the pathogenesis of age-related cataracts [9]. In our study, trichostatin A (TSA, an HDAC inhibitor) corrected the anacardic acid (AA, an HAT inhibitor)-induced imbalance between HATs and HDACs, resulting in enhancing SOD1 expression by reversing histone acetylation. The TSA-induced inhibition of proliferation, migration and epithelial mesenchymal transition (EMT) in HLECs maintains lens transparency [10].

Oxidative stress has been shown to play an important role in the pathogenesis of age-related cataracts [11], and disordered antioxidantion has been shown to aggravate cataracts in experimental models [12]. The exposure of Ultraviolet-B (UVB) also contributes to the development of age-related cataracts (ARCs). UVB exposure can alter gene expression, potentially involving epigenetic changes such as histone acetylation and/or DNA methylation [13]. Accordingly, anti-inflammation and antioxidation have been introduced to treat cataracts [11].

Some clinical investigations have indicated that HDACis are generally well tolerated and have antioxidant effects $[5,8,14]$. The ketone body $\beta$-hydroxybutyrate $(\beta \mathrm{OHB})$ has recently been recognized as an specific endogenous inhibitor of class I HDACs [15]. Studies have shown that $\beta O H B$ treatment increases histone acetylation of FOXO3A and MT2 promoters, and FOXO3A and MT2 genes are also activated by consumption of HDAC1 and HDAC2. Furthermore, treatment of mice with $\beta \mathrm{OHB}$ confers massive protection against oxidative stress [16].

In our study, we explored the protective effects of HDACis on UVB-treated HLECs. We also investigated the intervention related oxidative stress changes in HLECs.

\section{Materials and methods}

\section{Group setting}

Human lens epithelium B3 (HLE-B3) cells were cultured in vitro and divided into seven subgroups for each $\mathrm{HDACi}$ as follows. Group 1: normal control group (without UVB irradiation). Group 2: UVB exposure group. Group 3: dimethyl sulfoxide (DMSO) group (cells treated with DMSO, with the same UVB dosage as the UVB group). Groups 4, 5, 6 and 7: different concentrations of HDACis (concentrations 1, 2, 3 and 4). The concentrations of different HDACis were as follows: $\beta \mathrm{OHB}(4,8,16$ and 32 $\mathrm{mmol} / \mathrm{L})$, suberoylanilide hydroxamic acid (SAHA) (1, 2, 4 and $8 \mu \mathrm{mol} / \mathrm{L})$, TSA $(0.1,0.2,0.4$ and $0.8 \mu \mathrm{mol} / \mathrm{L})$, and valproic acid (VPA) (5, 10, 20 and $40 \mathrm{mmol} / \mathrm{L})$.

\section{Reagents and antibodies}

$\beta O H B, T S A, V P A$ and SAHA were obtained from Sigma (St Louis, Missouri, USA), dissolved in DMSO, stored at $-20^{\circ} \mathrm{C}$, and thawed before use. Propidium iodide (PI), Annexin V-FITC and DMSO were purchased from Sigma (St Louis). Fetal bovine serum (FBS) and Dulbecco's modified Eagle's medium (DMEM)were acquired from Gibco (Invitrogen, Grand Island, NY, USA). Antibodies against Bcl-2, BAX, caspase-3, SOD1, FOXO3A and Metallothionein (MT2) were purchased from Cell Signaling Technology and Santa Cruz Biotechnology (Santa Cruz, California, USA).

\section{Cell culture, treatment with HDACis and UVB radiation}

HLE-B3 cells were purchased from American Type Culture Collection (ATCC; Rockville, MD, CRL-11421) and cultured in DMEM containing 10\% FBS in a humidified $5 \% \mathrm{CO}_{2}$ atmosphere at $37^{\circ} \mathrm{C}$. HLE-B3 cells were cultured in six well plates in FBS-free DMEM for $24 \mathrm{~h}$ prior to treatment. Cells were cultured to $70 \%$ confluence and subsequently treated with different concentrations of HDACis. Then, HLE-B3 cells were treated with UVB light for $20 \mathrm{~min}$; the UVB dosage was $2 \mathrm{~W} / \mathrm{m}^{2}$ for $60 \mathrm{~min}$. Control HLECs were treated with DMSO the same concentration of. In preliminary experiments, this concentration of DMSO had no detrimental effect on HLECs. Following treatment, cells were harvested for cell viability assays and for mRNA and protein extraction.

\section{Cell viability (CCK-8)}

Different concentrations of HDACis were first incubated with human lens epithelial cells (HLECs) for $12 \mathrm{~h}$. Cell viability was envaluated with CCK-8 assay according to the manufacturer's protocol (Dojindo Laboratory, Kumamoto, Japan). Equal amount of HLECs were seeded into 96-well plates in a final volume of $100 \mu \mathrm{l}$ DMEM per well. After treatment, the samples and $10 \mu \mathrm{l}$ of CCK-8 kit reagent were co-incubated for $2 \mathrm{~h}$ at $37^{\circ} \mathrm{C}$. Absorbance was measured at $450 \mathrm{~nm}$ on a multi-well plate reader (Benchmark plus, Bio-Rad, Tokyo, 
Japan). The percentage of viable cells equation: ratio (\%) $=[\mathrm{OD}$ (treatment) $-\mathrm{OD}$ (the culture medium without cells)]/[OD (control) - OD (the culture medium without cells) $\times 100$. Each sample was evaluated in six replicates per assay (assays were performed three times).

\section{Apoptosis assessment}

The influence of HDACis on cell apoptosis was quantified using the Annexin-V Fluorescein Isothiocyanate (FITC) Apoptosis Detection Kit I (BD Biosciences, San Diego, $\mathrm{CA})$. Following a $12 \mathrm{~h}$ incubation with HDACis and a subsequent UVB exposure, HLECs were dispersed into a single cell suspension using $0.25 \%$ trypsin-0.02\% EDTA and then washed and labeled with propidium Iodide(PI) and Annexin V-FITC. Cell apoptosis was measured using a flow cytometer (BD Biosciences, San Jose, California, USA). All experiments were performed three times.

\section{Western blot assay}

HLECs were treated with different doses of HDACis and UVB and lysates were prepared from $1 \times 10^{7}$ cells. HLECs were lysed in RIPA buffer (Solarbio, USA), which contained a protease inhibitor cocktail (Beyotime, China) and phenylmethylsulfonyl fluoride (PMSF, Beyotime, China). The supernatant was collected after centrifugation at $12000 \mathrm{rpm}$ for $20 \mathrm{~min}$ at $4{ }^{\circ} \mathrm{C}$. The protein concentrations of each sample were measured using a BCA Protein Quantitation Kit (Beyotime, China). All samples were separated in equal amounts by $10 \%$ SDS-polyacrylamide gel electrophoresis (PAGE) (100 V for $90 \mathrm{~min}$ ) and transferred to polyvinylidine difluoride (PVDF) membranes (Millipore, Bedford, MA) using a transfer apparatus (BioRad) at $40 \mathrm{~mA}$ for $8 \mathrm{~h}$. Blocking buffer (5\% nonfat milk, $200 \mathrm{mM}$ $\mathrm{NaCl}, 50 \mathrm{mM}$ Tris, $0.05 \%$ Tween 20 ) was used for inhibiting nonspecific protein binding to the membrane. The blocked membranes were then incubated with primary antibodies against GAPDH (1:2000, Abcam), Bax (1:200, Santa Cruz), Bcl2 (1:200, Santa Cruz, USA), caspase-3 (1:500, Abcam, Inc., Cambridge, MA, USA), SOD1 (1:10000, Abcam), FOXO3A (1:5000, Abcam) and MT2 (1:1000, Abcam) at $4{ }^{\circ} \mathrm{C}$ overnight. Next, the membrane was washed with TBST $(20 \mathrm{mM}$ Tris, $500 \mathrm{mM} \mathrm{NaCl}, 0.1 \%$ Tween 20) at $28^{\circ} \mathrm{C}$ for three times ( 5 min each time) and then incubated with HRP-conjugated secondary antibodies (1:4000; Santa Cruz, USA) at $28^{\circ} \mathrm{C}$ for $2 \mathrm{~h}$. Then, the membrane was washed with TBST four times (15 min each time) at $28{ }^{\circ} \mathrm{C}$. The bands were visualized by enhanced chemiluminescence (ECL) (Pierce, Rockford, IL). The film was scanned and measured using ImageQuant software (Molecular Dynamics, Sunnyvale, CA).

\section{Enzyme-linked immunosorbent assay (ELISA)}

HLECs from HDACi-treated groups and controls were used to quantitatively detect SOD1 using a commercially available ELISA (AB Frontier). Absorbance was assessed at $450 \mathrm{~nm}$ using the 680XR Microplate reader (Biorad, Hercules, USA). For the SOD1 ELISA, primary antibody was a rabbit monoclonal anti-SOD1 (Sigma) antibody and the secondary antibody was a goat anti-rabbit antibody. The analysis of SOD1 levels was performed by the kit manufacturer. The SOD1 standard curve was generated by linear regression analysis in each group.

\section{Measurement of oxidative stress}

Total antioxidant capacity (T-AOC), reactive oxygen species (ROS), malondialdehyde (MDA) and superoxide dismutase (SOD) levels were quantified according to instructions provided with the detection kits (Jiancheng Bioengineering Institute, Nanjing, China) in order to determine intracellular antioxidant conditions.

\section{Assessment of mitochondrial membrane potential (MMP)}

We prepared JC-1 fluorescent probes (Beyotime, Hangzhou, China) in order to analyze changes in MMP after treatments. The JC-1 solution were incubated with HLECs for $20 \mathrm{~min}$ at $37^{\circ} \mathrm{C}$ in the dark, and then fluorescence microscopy and flow cytometry were used to analyze MMP., MMP is high under normal conditions and displays red fluorescence. Meanwhile, lower MMP, which is an indicator of early apoptosis, is indicated by green fluorescence. MMP was detected using CellQuest software version 3.3 (BD Biosciences, Franklin Lakes, NJ, USA) and the red:green ratio was calculated.

\section{Real-time PCR}

Trizol Reagent (Invitrogen, Gaithersburg, MD, USA) was used for total RNA isolation and the SuperScript II Reverse Transcriptase kit (Invitrogen, Carlsbad, CA, USA) was used for reverse-transcription. Real-time PCR analysis was performed using the SYBR-Green PCR Master Mix (Applied Biosystems, Foster City, CA, USA). Bcl-2, BAX, caspase-3, SOD1, FOXO3A and MT2 expression levels were shown relative to the indicated control samples after normalized to GADPH levels. All primer sequences are listed in Table 1.

\section{Data analysis}

All statistical analyses were performed using SPSS for Windows (13.0, SPSS, Inc., Chicago, IL, USA). Each value is the mean of at least three separate experiments in each group. The means, standard deviations, and coefficients of variation (CVs) were calculated. Mean values are reported along with the standard deviation of the mean $( \pm S D)$ unless otherwise stated. Two-sided pairwise comparisons were conducted. Comparisons among experiments were performed by one-way analysis of variance (ANOVA). $P$ values $<0.05$ were considered 
Table 1 The primers used for real-time PCR

\begin{tabular}{|c|c|c|c|}
\hline Gene & Primer $\mathrm{F}$ & Primer $\mathrm{R}$ & Size (bps) \\
\hline $\mathrm{BCL} 2$ & 5' GACTTCGCCGAGATGTCCAG 3' & 5' GCCGGTTCAGGTACTCAGTC 3' & 220 \\
\hline BAX & 5' AGACCGTGACCATCTITGTG 3' & $5^{\prime}$ TCCCGAAGGAGGTTTATTACCC 3' & 226 \\
\hline caspase 3 & 5' AACTGGACTGTGGCATTGAG 3' & 5' ACAAAGCGACTGGATGAACC 3' & 161 \\
\hline SOD1 & 5' GGTGCTGGTTTGCGTCGTAG 3' & 5' GCCTTCGTCGCCATAACTCG 3' & 102 \\
\hline FOXO3a & 5' CCAGGGTAAAGTCAAGTG 3' & 5' GCAGGGTCTCAACATAAG 3' & 210 \\
\hline MT2 & 5' CCTGCAAATGCAAAGAGTG 3' & 5' ATCCAGGTTTGTGGAAGTC 3' & 189 \\
\hline GAPDH & 5' CACCCACTCCTCCACCTTTG 3' & 5' CCACCACCCTGTTGCTGTAG 3' & 110 \\
\hline
\end{tabular}

statistically significant and those $<0.01$ were considered highly significant.

\section{Results}

HLEC viability and apoptosis following HDACi treatment HLECs were treated with indicated concentrations of HDACis for $12 \mathrm{~h}$ prior to UVB exposure, and then the influence of HDACis on both cell viability and apoptosis were assessed.

CCK- 8 assays were used to determine the cell viability of a wide range of HDACi concentrations in HLECs. All the groups of indicated HDACi concentrations were exposed to UVB before CCK-8 assay. $\beta \mathrm{OHB}$ and SAHA showed a dose-dependent decrease in cell viability. $\beta \mathrm{OHB}$ and VPA had no protective effects in UVB-treated HLECs. However, SAHA $(1 \mu \mathrm{mol} / \mathrm{L}: P=0.007,2 \mu \mathrm{mol} / \mathrm{L}: P=$ $0.023)$ and TSA $(0.2 \mu \mathrm{mol} / \mathrm{L}: P=0.031)$ showed mild protective effects on cell viability after UVB exposure (Fig. 1).

We next assessed Apoptosis of HLECs were assessed using Annexin V-FITC/PI flow cytometry. As expected, the proportion of apoptotic cells increased after UVB exposure. However, only SAHA $(1 \mu \mathrm{mol} / \mathrm{L}: P=0.001)$ was able to decrease apoptosis rates in UVB-treated HLECs (Fig. 2). Higher concentrations of HDACis resulted in increased levels of cell apoptosis.

Effects of HDACis on Bcl-2, BAX, caspase-3, SOD1, FOXO3A and MT2 mRNA expression in UVB-treated HLECs Bcl-2 and SOD1 mRNA levels were appatently suppressed in UVB-treated HLECs (Fig. 3). However, caspase-3,
FOXO3A, BAX and MT2 levels were significantly elevated after UVB exposure. $\beta \mathrm{OHB}(4 \mathrm{mmol} / \mathrm{L}: P=0.047)$ and TSA $(0.2 \mathrm{~mol} / \mathrm{L}: P=0.018)$ had increased the BCL-2 expression. TSA $(0.2 \mathrm{~mol} / \mathrm{L}: P=0.024)$ had increased the on SOD1 expression. TSA $\left(0.2 \mathrm{~mol} / \mathrm{L}: P_{B A X}=0.004, P_{\text {caspase- } 3}\right.$ $=0.000)$ and SAHA $\left(1 \mu \mathrm{mol} / \mathrm{L}: P_{B A X}=0.014, P_{\text {caspase }-3}=\right.$ $0.005)$ suppressed BAX and caspase- 3 expression. TSA $\left(0.2 \mathrm{~mol} / \mathrm{L}: P_{\text {FOXO3A }}=0.003, P\right.$ MT2 $=0.024,0.8 \mathrm{~mol} / \mathrm{L}: P$ FOXO3A $\left.=0.037, P_{\text {MT2 }}=0.005\right)$ and SAHA $(1 \mu \mathrm{mol} / \mathrm{L}: P$ FOXO3A $=0.010, \quad P_{\text {MT2 }}=0.009,2 \mu \mathrm{mol} / \mathrm{L}: \quad P$ FOXO3A $=$ $0.021, \quad P$ MT2 $=0.026$ ) suppressed the expression of FOXO3A and MT2. The HDACi-induced protective effects were not strictly dose-dependent.

\section{HDACi attenuates oxidative stress in HLECs after UVB exposure}

As shown in Figs. 4 and 5, ROS and MDA levels were obviously enhanced in UVB-treated HLECs, while T-AOC and SOD levels were declined. However, after HDACi administration, MDA and ROS levels were relatively decreased while T-AOC and SOD levels were elevated. SOD levels were increased in UVB-treated HLECs following treatment with $\beta \mathrm{OHB}(4 \mathrm{mmol} / \mathrm{L}: P=0.005)$, SAHA $(1 \mu \mathrm{mol} / \mathrm{L}: P=$ $0.002)$ and TSA $(0.1 \mathrm{~mol} / \mathrm{L}: P=0.013,0.2 \mathrm{~mol} / \mathrm{L}: P=0.010)$. T-AOC levels were increased in UVB-treated HLECs following treatment with SAHA $(2 \mu \mathrm{mol} / \mathrm{L}: P=0.006)$. MDA levels were decreased in UVB-treated HLECs following treatment with TSA $(0.2 \mathrm{~mol} / \mathrm{L}: P=0.003,0.8 \mathrm{~mol} / \mathrm{L}: P=$ 0.029). ROS levels were decreased in UVB-treated HLECs
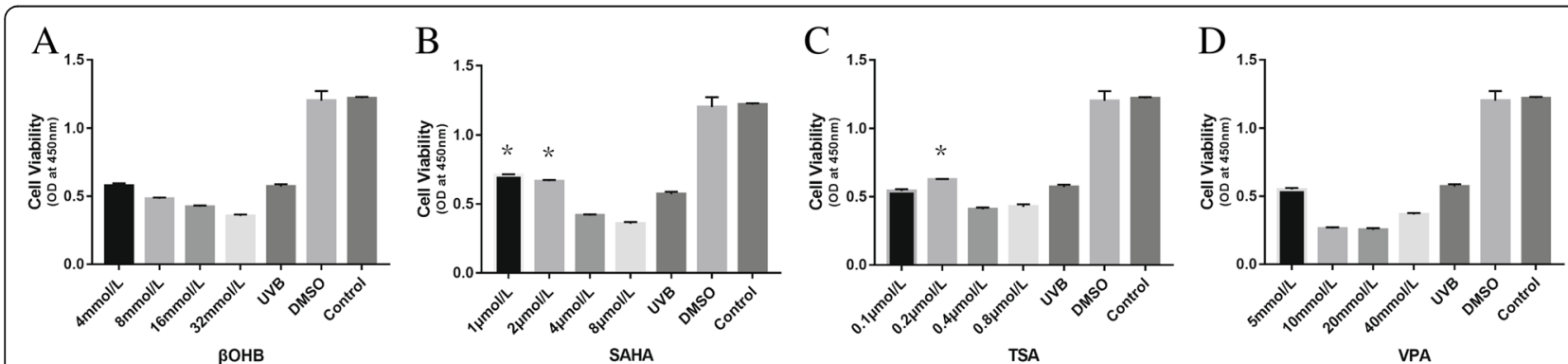

Fig. 1 Cell viability of HLECS after HDACi treatment. a: $\beta O H B$, b: SAHA, c: TSA, d: VPA. $\beta O H B$ and VPA had no protective effects in UVB-treated HLECs. However, SAHA $(1 \mu \mathrm{mol} / \mathrm{L}, 2 \mu \mathrm{mol} / \mathrm{L})$ and TSA $(0.2 \mu \mathrm{mol} / \mathrm{L})$ showed mild protective effects on cell viability after UVB exposure. ${ }^{*} P<0.05$ 

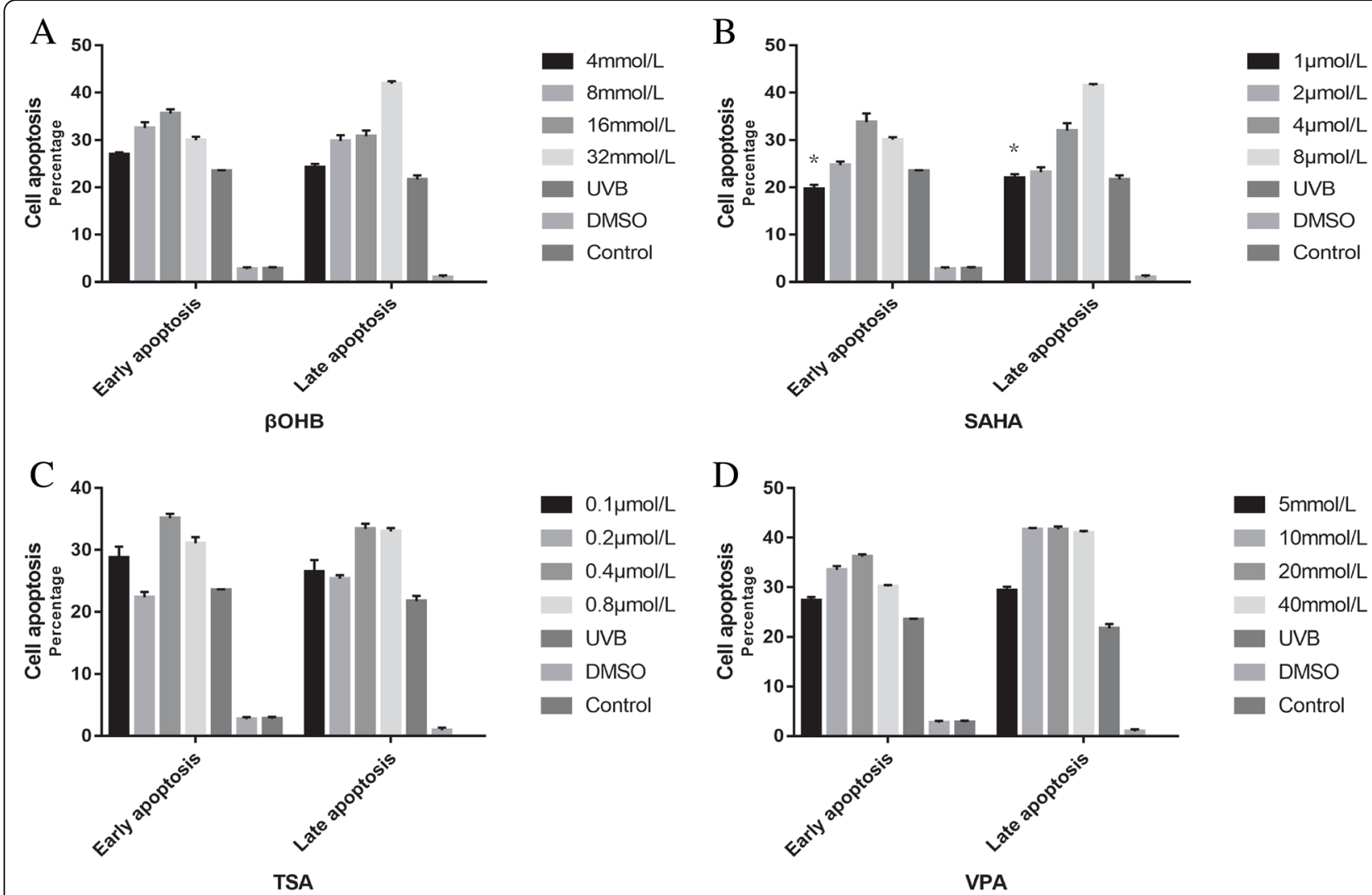

Fig. 2 HDACi showed mild anti-apoptosis effect on HLECs after UVB exposure. $\mathbf{a}$ : $\beta O H B$, b: SAHA, c: TSA, d: VPA. The proportion of apoptotic cells increased after UVB exposure. However, only SAHA $(1 \mu \mathrm{mol} / \mathrm{L})$ was able to decrease apoptosis rates in UVB-treated HLECs. Higher concentrations of HDACis resulted in increased levels of cell apoptosis. ${ }^{*} P<0.05$

following treatment with $\beta \mathrm{OHB}(4 \mathrm{mmol} / \mathrm{L}: \quad P=0.008)$, SAHA $(1 \mu \mathrm{mol} / \mathrm{L}: P=0.001,2 \mu \mathrm{mol} / \mathrm{L}: P=0.001)$ and TSA (0.2 mol/L: $P=0.001)$.

\section{HDACis upregulate SOD1 expression levels and activity in HLECs}

Western blotting results demonstrated that SOD1 expression levels were upregulated following HDACi administration (Figs. 6 and 7). SOD1 levels significantly increased in the $\beta \mathrm{OHB}(4 \mathrm{mmol} / \mathrm{L}: P=0.005)$, SAHA $(1 \mu \mathrm{mol} / \mathrm{L}: P=0.001,2 \mu \mathrm{mol} / \mathrm{L}: P=0.004)$, TSA $(0.1 \mathrm{~mol} /$ L: $P=0.013,0.2 \mathrm{~mol} / \mathrm{L}: P=0.010)$ and VPA $(5 \mathrm{mmol} / \mathrm{L}$ : $P=0.020)$ groups after UVB exposure.

\section{HDACis display mild anti-apoptotic effects in UVB-treated HLECS on MMP}

We also analyzed the effect of HDACis on MMP using JC-1. The control and DMSO-treated cells showed weak green fluorescence and strong red fluorescence, indicating high MMP. UVB exposure to cells accelerated the depolarization of the mitochondrial membrane, which manifested as stronger green fluorescence and. Weaker red fluorescence. However, we found that HDACis were not able to reduce the depolarization of the mitochondrial membrane induced by UVB exposure (Fig. 8). These results suggested that HDACis could not protect against oxidative stress-induced changes in MMP. Taken together, these results indicate that HDACis exert a potent anti-apoptotic effect on UVB-treated HLECs.

\section{Discussion}

HLECs compose the cell layer of the eye that is first exposed to environmental and oxidative insult. Many pivotal factors are involved in the pathogenesis of cataracts, including oxidative stress. Oxidative stress plays an important role in the cross-linking and aggregation of lens proteins, oxidation, induction of lens epithelial cell apoptosis and aging [11]. Therefore, antioxidant treatments have been considered to treat cataracts [12]. HDACis boast a celebrated history: they were initially studied for their ability to increase gene expression [1] but in recent years have also been discovered to have potent immunomodulatory, anti-inflammatory, antioxidant, and anti-cancer functions [6-8]. These antioxidant properties suggest that HDACis may be potential therapies for age-related diseases including cataracts [17-19]. 

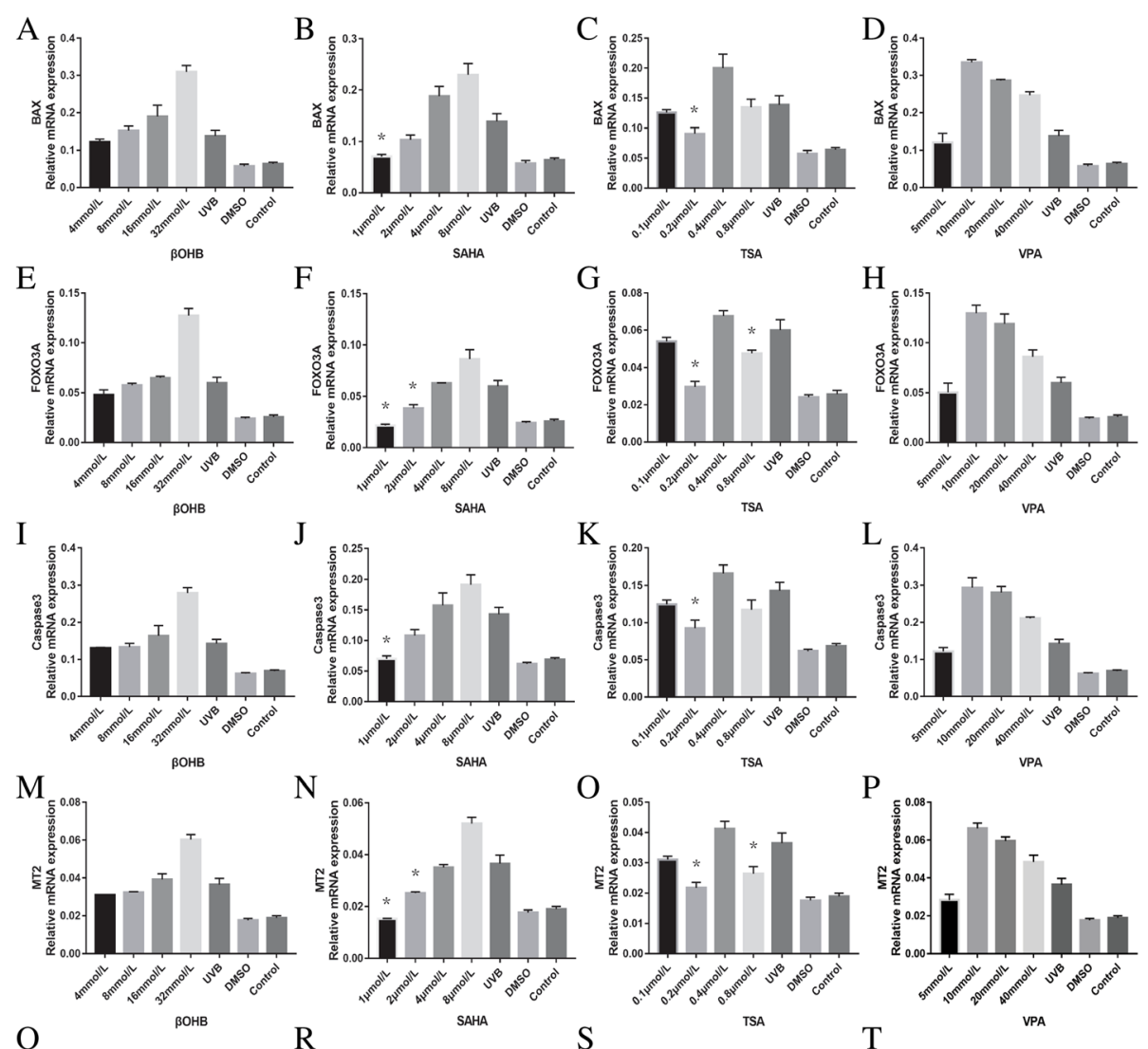

$\mathrm{O}$
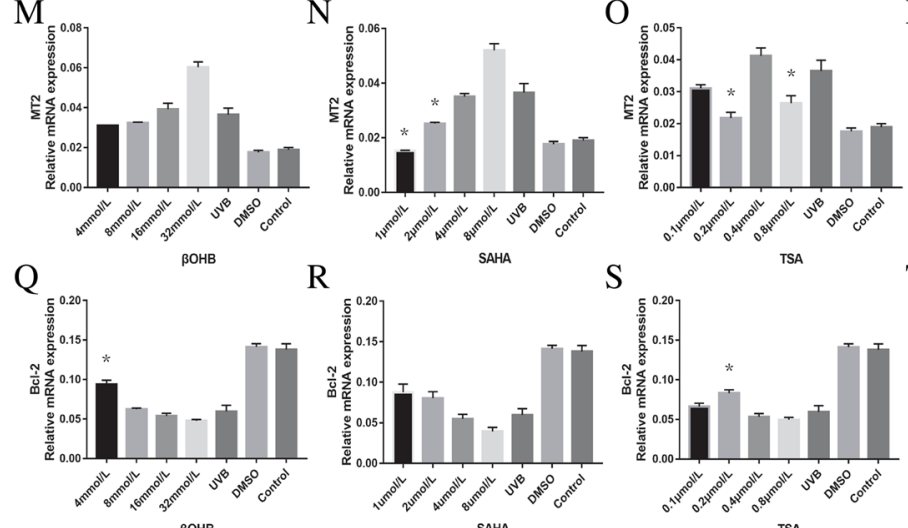

$\mathrm{P}$
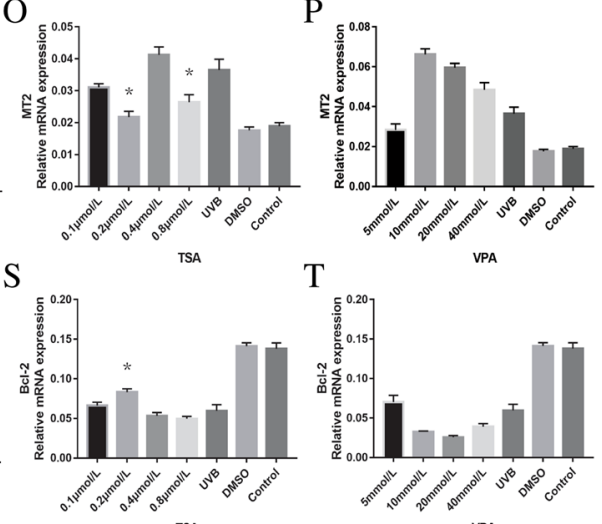

$\mathrm{T}$
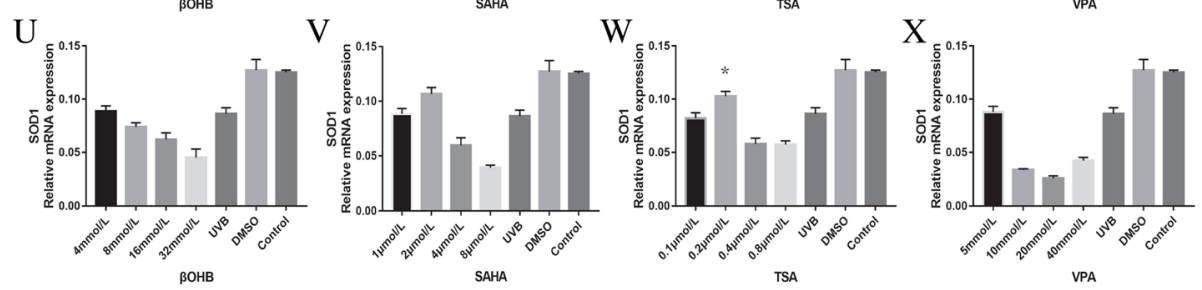

Fig. 3 Effects of HDACi on the expressions of BCl-2, BAX, caspase-3, SOD1, FOXO3A and MT2 mRNA in UVB-treated HLECs. BAX: a-d, FOXO3A: e-h, Caspase3: i-l, MT2:m-p, Bcl-2: q-t, SOD1: u-x. $\beta O H B(4 \mathrm{mmol} / \mathrm{L})$ and TSA $(0.2 \mathrm{~mol} / \mathrm{L})$ had protective effects on BCL-2 expression. TSA (0.2 mol/L) had a protective effect on SOD1 expression. TSA $(0.2 \mathrm{~mol} / \mathrm{L})$ and SAHA $(1 \mu \mathrm{mol} / \mathrm{L})$ suppressed BAX and caspase-3 expression. TSA $(0.2 \mathrm{~mol} / \mathrm{L}, 0.8$ $\mathrm{mol} / \mathrm{L})$ and $\mathrm{SAHA}(1 \mu \mathrm{mol} / \mathrm{L}, 2 \mu \mathrm{mol} / \mathrm{L})$ suppressed the expression of FOXO3A and MT2. The HDACi-induced protective effects were not strictly dose-dependent. ${ }^{*} P<0.05$

In our present study, we analysed the the potential effect of HDACis on cataracts. We used HLE-B3 cells in our experiments because these cells are considered the main cell type affected by UVB radiation and thus represent a potential target for intervention.

In our study, we evaluated the underlying effects of HDACis on UVB-injured HLECs. We selected four HDACis based on the potential to translate our findings into clinical studies. $\beta \mathrm{OHB}$, which mainly produced by hepatocytes, serves as an alternative source of ATP in low-glucose conditions by carrying energy from the liver to peripheral tissues [20]. In recent studies, $\beta \mathrm{OHB}$ has been shown to act as an endogenous HDACi and to exert important cellular signaling effects [20-22]. $\beta \mathrm{OHB}$ treatment also elevates histone acetylation at the promoters of FOXO3A and MT2 involved in anti-oxidation 


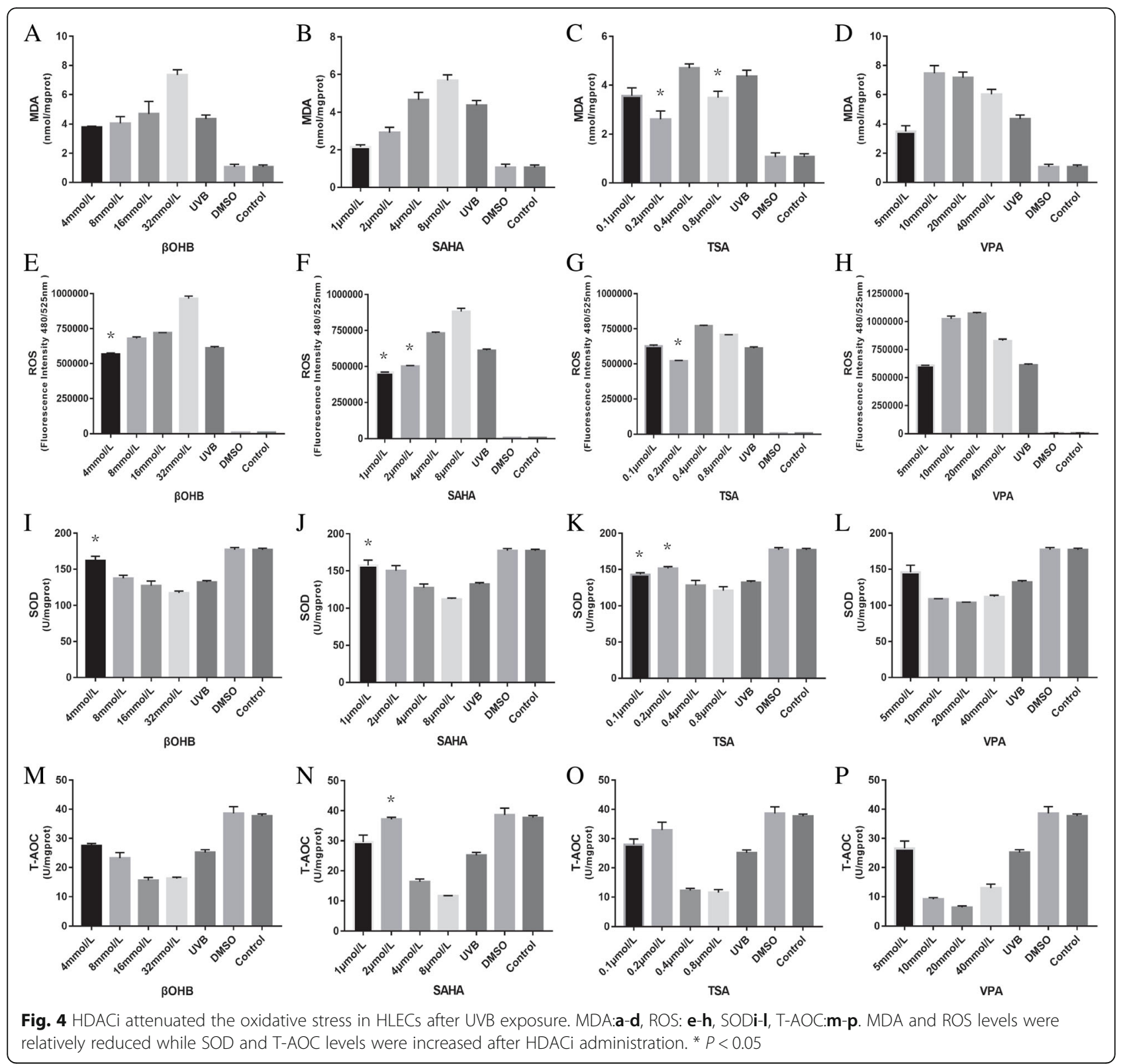

[21]. SAHA (vorinostat, Zolinza ${ }^{\circ}$ ) is the lead compound in a new class of HDACis and is the first drug in this class to be clinically approved for the treatment of cancer. SAHA has been shown to affect multiple proteins associated with cell migration, proliferation and gene expression [23]. SAHA functions through multiple mechanisms, many of which involve its ability to serve as an NO donor under oxidizing conditions $[24,25]$. TSA is a classical, noncompetitive and nonselective HDAC inhibitor and which derived from the Streptomyces species as a fermentation product [26]. A recent study found that TSA can suppress EMT and proliferation of the HLEC lines SRA01/04 and HLEB3, and can prevent the formation of posterior capsule opacification [27]. VPA, a class
I HDAC inhibitor, is used clinically as an antiepileptic drug and for some painful neuropathies; it has a low toxicity profile and a complex pharmacological mechanism $[28,29]$. Recent studies have reported that VPA exerts its antitumor effects in various cancers through HDAC inhibition and clinical studies of this drug are ongoing $[30,31]$. The result of our study showed obvious variety in the effect of different HDACis on HLECs after UVB exposure, which might be explained by the mechanisms of actions are quite different among these four HDACis,

Accumulating evidence reveals that oxidative stress is a probable contributor to cataract formation [11, 12]. MDA levels reflect the extent of oxidative damage to cell membranes [32]. SOD is the first line of defense against 
A

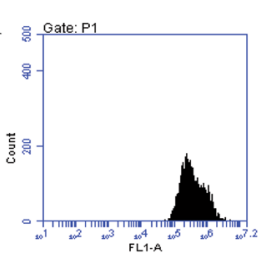

$3 \mathrm{OHB} 4 \mathrm{mmol} / \mathrm{L}$

E

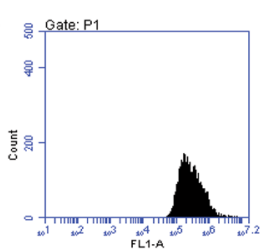

SAHA $1 \mu \mathrm{mol} / \mathrm{L}$

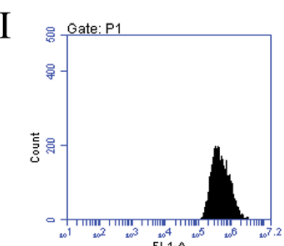

TSA $0.1 \mu \mathrm{mol} / \mathrm{L}$

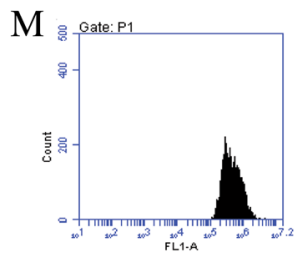

VPA $5 \mathrm{mmol} / \mathrm{L}$

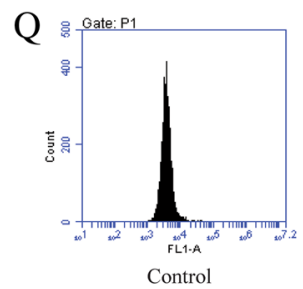

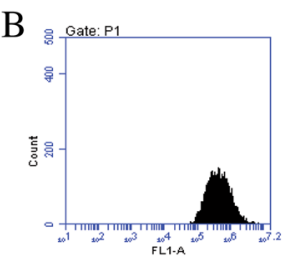

BOHB $8 \mathrm{mmol} / \mathrm{L}$

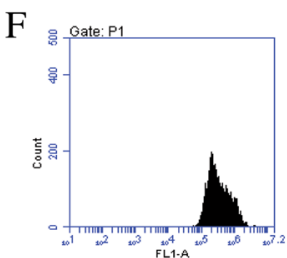

SAHA $2 \mu \mathrm{mol} / \mathrm{L}$

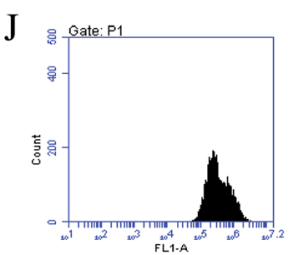

TSA $0.2 \mu \mathrm{mol} / \mathrm{L}$

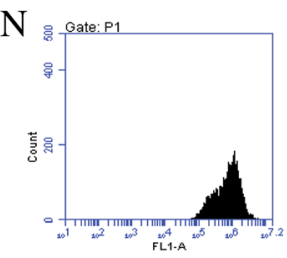

VPA $10 \mathrm{mmol} / \mathrm{L}$

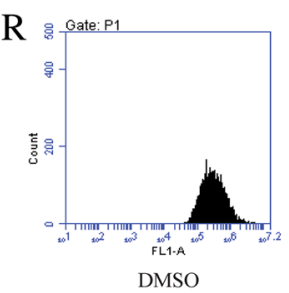

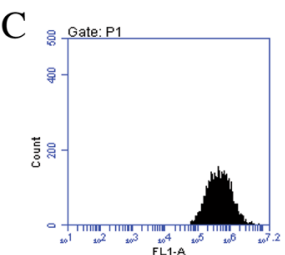

BOHB 16mmol/L

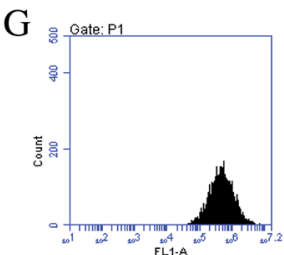

SAHA $4 \mu \mathrm{mol} / \mathrm{L}$

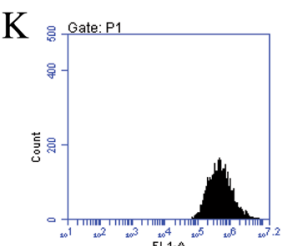

TSA $0.4 \mu \mathrm{mol} / \mathrm{L}$

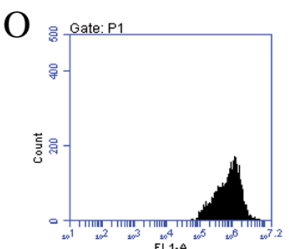

VPA $20 \mathrm{mmol} / \mathrm{L}$

S

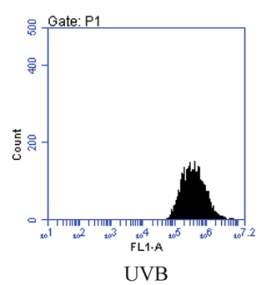

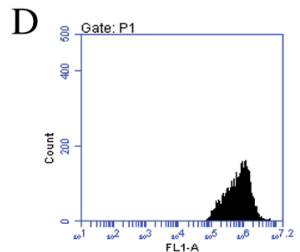

$3 \mathrm{OHB} 32 \mathrm{mmol} / \mathrm{L}$

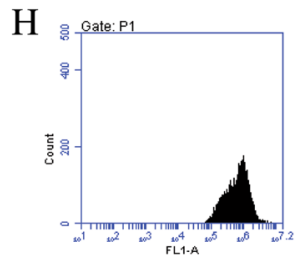

SAHA $8 \mu \mathrm{mol} / \mathrm{L}$

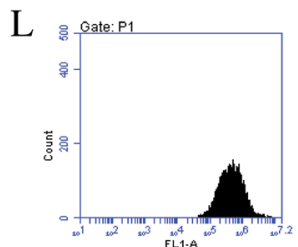

TSA $0.8 \mu \mathrm{mol} / \mathrm{L}$

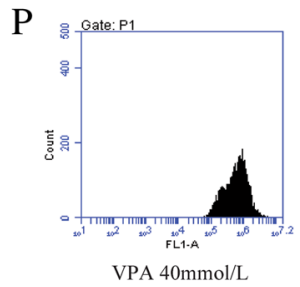

VPA $40 \mathrm{mmol} / \mathrm{L}$

Fig. 5 The ROS levels in HLECS treated with/without HDACi after UVB exposureßOHB:a-d, SAHA: e-h, TSA:-I, VPA:m-p, Control group: Q, DMSO group: R, UVB group: $S$
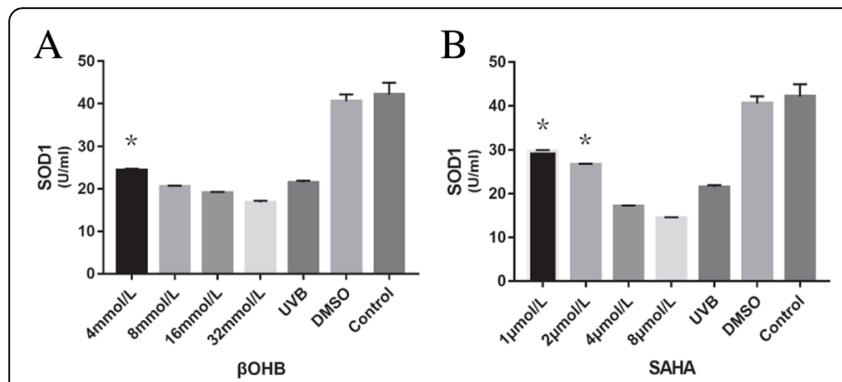

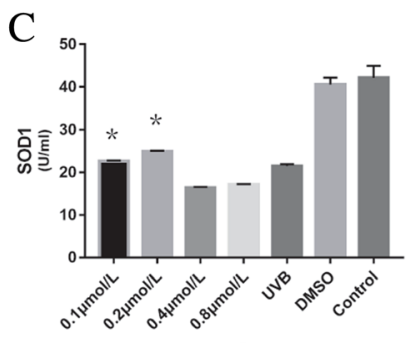

TSA

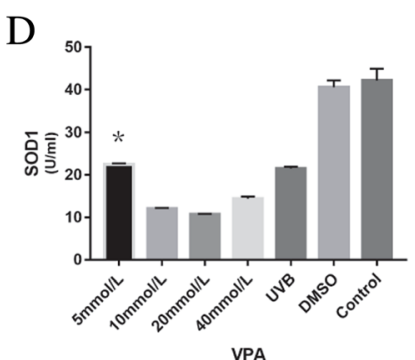

VPA

Fig. 6 HDACi upregulated the expression level and activity of SOD1 in HLECSA: $\beta O H B$, B: SAHA, C: TSA, D: VPA. SOD1 levels significantly increased in the $\beta O H B(4 \mathrm{mmol} / \mathrm{L})$, SAHA $(1 \mu \mathrm{mol} / \mathrm{L}, 2 \mu \mathrm{mol} / \mathrm{L})$, TSA $(0.1 \mathrm{~mol} / \mathrm{L}, 0.2 \mathrm{~mol} / \mathrm{L})$ and VPA $(5 \mathrm{mmol} / \mathrm{L})$ groups after UVB exposure. ${ }^{*} P<0.05$ 


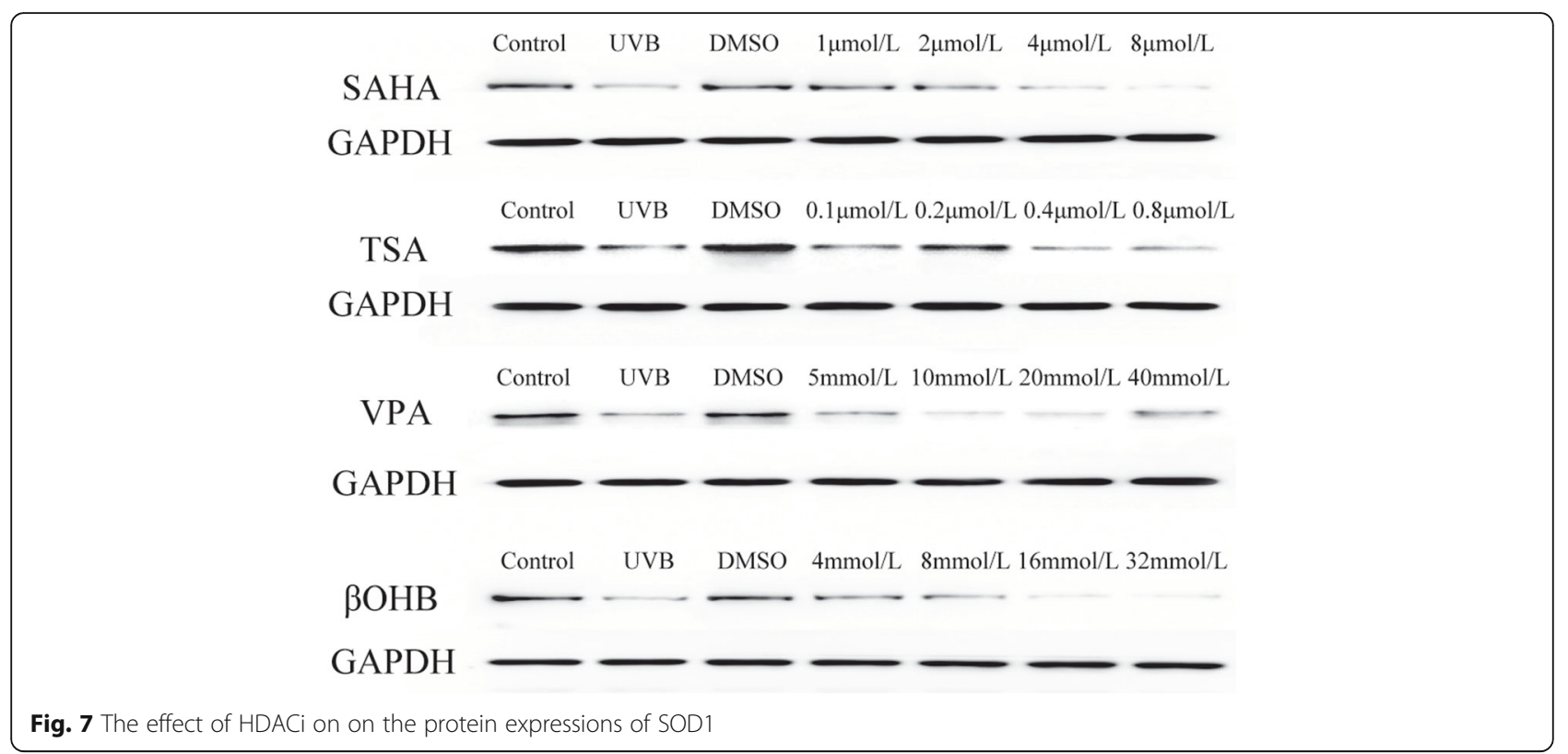

ROS, and acts as an important factor in the antioxidant enzymatic defense system, which. T-AOC levels reflect the overall endogenous cellular antioxidant capability [33]. Hence, in the present study, SOD, ROS, MDA and T-AOC levels were evaluated to assess the oxidative stress in HLECs. We showed that, ROS and MDA levels were substantially elevated while T-AOC and SOD levels were decreased after UVB exposure. In contrast, HDACi treatment decreased MDA and ROS levels and simultaneously enhanced SOD and T-AOC levels. These results indicated that HDACis could decrease UVB-induced oxidative stress, which might lead to promising applications for cataract treatment.

Oxidative stress can also trigger the apoptosis of LECs. Previous studies have shown that increased FOXO3A expression elevates the cell's ability to resist oxidative stress [34]. The proteins Bax and Bcl-2 are widely recognized as the most important regulators of apoptosis. The specific ratio of $\mathrm{Bcl}-2$ to $\mathrm{BAX}$ gene expression is critical in determining cell fate [35]. Caspases are important indicators of apoptosis and caspase- 3 is a major downstream effector caspase in the LEC apoptotic process [36]. Following UVB exposure, the extent of apoptosis as well as the transcription of BAX, caspase 3, FOXO3A and MT2 in HLECs were significantly increased, indicating that oxidative damage was stimulated. We also found that Bcl-2 and SOD1 transcription decreased in HLECs following UVB exposure, indicating that HLECs have antioxidant capabilities.

To explore the potential protective effects of HDACis on apoptosis in HLECs induced by UVB as a classical oxidative stress [37]. we used a range of HDACi concentrations as a dose-response experiment. The doses chosen for our experiments were based on published studies that reported the ranges required to inhibit HDACs [4-8]. The results indicated that low concentrations of HDACis exerted a certain extent of protective effects against oxidization and inhibitory effects against cell apoptosis. Our study noted that HDACi prevented UVB-induced elevation of BAX, caspase 3, Foxo3a and MT2, but not in a dose-dependent manner. This result indicates that HDACi is able to modulation of $\mathrm{Bax} / \mathrm{Bcl}-2$ expression in order to protect against UVB-induced apoptosis.

Several of the currently available HDACis have antioxidant properties, whereas associated with obvious toxicity [38]. This maily due to none class-specific inhibitor and complexity of cellular pathways involved [39]. Our study showed that high concentrations of HDACis manifested in high toxicity that outweighed that antioxidant effects. Identification of more selective HDACis with lower toxicity [38] will be important for antioxidant-based treatments with increased potency. As demonstrated in previous studies, significantly lower HDACi concentrations can be used in models of autoimmune diseases compared with those required to reduce tumors in mice [40]. These results indicate that lower concentrations may be sufficient to exert antioxidant effects.

The future development of HDACis should be focused on selective inhibitors [41]. It should also be expected that different HDACis will be most effective depending on the dominant cell type in a particular disease. Our findings as a preliminary study provided possible direction for future research. The exact mechanism of HDACis still need further investigation. More precise measurements were also needed to accurately evaluate the role of HDACis. Further studies should focus on 
A

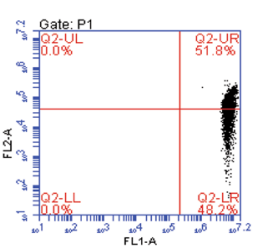

$\beta \mathrm{OHB} 4 \mathrm{mmol} / \mathrm{L}$

E

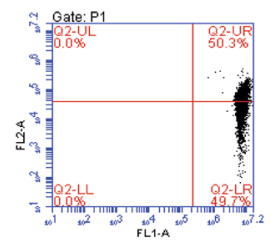

SAHA $1 \mu \mathrm{mol} / \mathrm{L}$

I

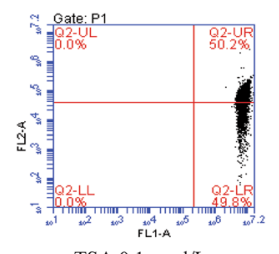

TSA $0.1 \mu \mathrm{mol} / \mathrm{L}$

M

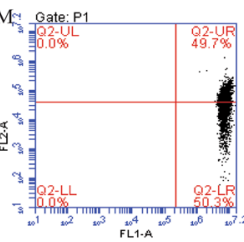

VPA $5 \mathrm{mmol} / \mathrm{L}$

\section{Q}

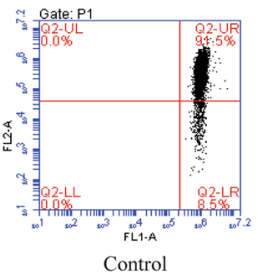

B

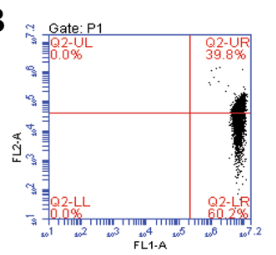

BOHB $8 \mathrm{mmol} / \mathrm{L}$

F

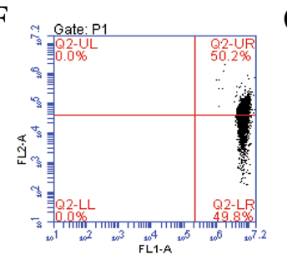

SAHA $2 \mu \mathrm{mol} / \mathrm{L}$

$\mathrm{J}$

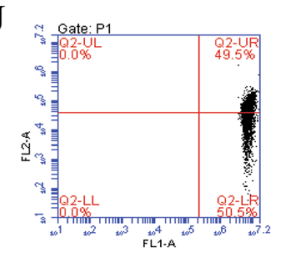

TSA $0.2 \mu \mathrm{mol} / \mathrm{L}$

$\mathrm{N}$

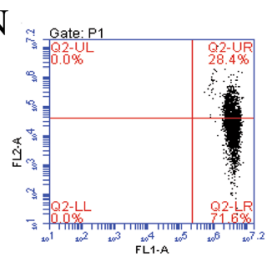

VPA $10 \mathrm{mmol} / \mathrm{L}$

$\mathrm{R}$

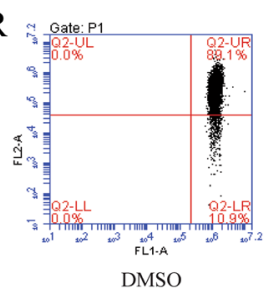

C

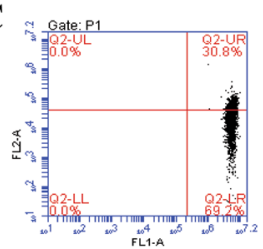

BOHB $16 \mathrm{mmol} / \mathrm{L}$

G

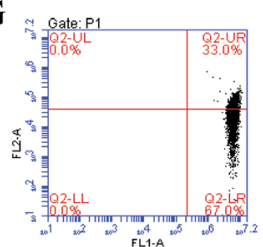

SAHA $4 \mu \mathrm{mol} / \mathrm{L}$

K

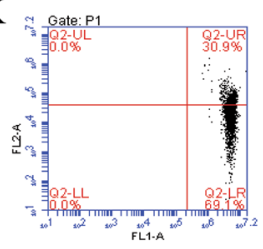

TSA $0.4 \mu \mathrm{mol} / \mathrm{L}$

$\mathrm{O}$

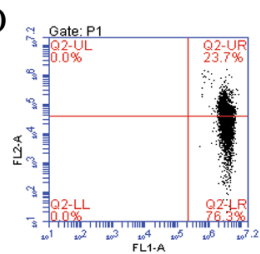

VPA $20 \mathrm{mmol} / \mathrm{L}$

S

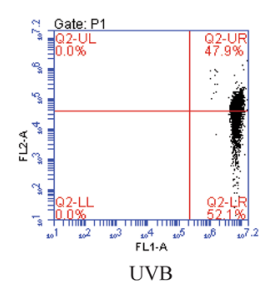

D

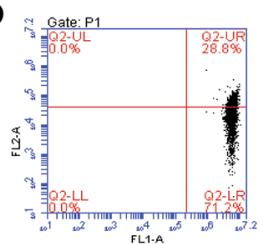

BOHB 32mmol/L

$\mathrm{H}$

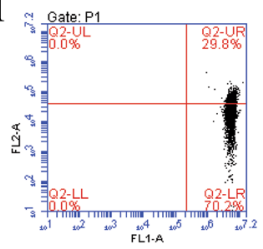

SAHA $8 \mu \mathrm{mol} / \mathrm{L}$

L

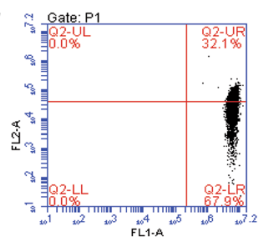

TSA $0.8 \mu \mathrm{mol} / \mathrm{L}$

$\mathrm{P}$

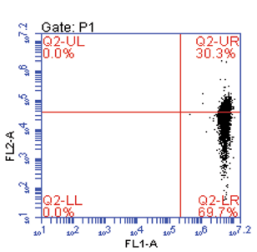

VPA $40 \mathrm{mmol} / \mathrm{L}$

Fig. 8 The effect of HDACi on MMP in HLECS after UVB exposure. $\beta O H B: \mathbf{a}-\mathbf{d}$, SAHA: $\mathbf{e}-\mathbf{h}$, TSA:i-l, VPA:m-p, Control group: $\mathbf{q}$, DMSO group: $\mathbf{r}$, UVB group: $\mathbf{s}$. UVB exposure to cells facilitates the depolarization of the mitochondrial membrane. However, HDACis were not able to reduce the UVBinduced depolarization of the mitochondrial membrane

determining the efficacy, safety, and pharmacokinetic properties of HDACis. Specific studies should also focus on identifying the metabolic pathways associated with HDACi antioxidant activities. Moreover, a comprehensive overview of HDACi-related adverse effects should be given.

\section{Conclusions}

In summary, the current study provides direct evidence that few low concentrations of HDACis exert mild antioxidant effects on UVB-treated HLECs. These results suggest that HDACis may be a possible therapy for the prevention and treatment of cataracts.

\section{Abbreviations}

ARCs: age-related cataracts; DMEM: Dulbecco's modified Eagle's medium; DMSO: dimethyl sulfoxide; ECL: enhanced chemiluminescence;

ELISA: Enzyme-linked Immunosorbent Assay; EMT: epithelial mesenchymal transition; FBS: fetal bovine serum; FITC: fluoresceine isothiocyanate;

HATs: histone acetyltransferases; HDACis: histone deacetylase inhibitors; HDACs: histone deacetylases; HLE-B3: human lens epithelium B3; HLECs: human lens epithelial cells; MDA: malondialdehyde; MMP: Mitochondrial Membrane Potential; MT2: Metallothionein; PAGE: polyacrylamide gel electrophoresis; PI: propidium lodide; PMSF: phenylmethylsulfonyl fluoride; PVDF: polyvinylidine difluoride; ROS: reactive oxygen species; SAHA: suberoylanilide hydroxamic acid; SOD: superoxide dismutase; T-AOC: total antioxidant capacity; TSA: trichostatin A; UVB: ultraviolet-B; VPA: valproic acid; $\beta O H B$ : $\beta$ hydroxybutyrate

Acknowledgements Not applicable. 


\section{Funding}

This research was funded by research grants from National Natural Science Foundation of China $(81300746,81300806)$, the scientific research program of Shanghai municipal health and Family Planning Commission (20174Y0186) and Natural Science Foundation of Shanghai (16ZR1405200). The funding organization had no role in the design or conduct of this research.

\section{Availability of data and materials}

The datasets used and/or analysed during the current study are available from the corresponding author on reasonable request.

\section{Authors' contributions}

$X Q$ and XR acquired and interpreted data analyzed, made substantial contributions to conception and design, had been involved in drafting the manuscript. JY made substantial contributions to conception and design, revising the manuscript critically for important intellectual content. YL made substantial contributions to conception and design, revising the manuscript critically for important intellectual content. All authors give final approval of the version to be published, have participated sufficiently in the work to take public responsibility for appropriate portions of the content, and agreed to be accountable for all aspects of the work in ensuring that questions related to the accuracy or integrity of any part of the work are appropriately investigated and resolved. Xiaodi Qiu and Xianfang Rong contributed equally to this work.

\section{Ethics approval and consent to participate}

Not applicable.

\section{Consent for publication}

Not applicable.

\section{Competing interests}

Professor Yi Lu is a member of the editorial board of BMC Ophthalmology.

\section{Publisher's Note}

Springer Nature remains neutral with regard to jurisdictional claims in published maps and institutional affiliations.

\section{Author details}

${ }^{1}$ Eye Institute, Eye and Ear, Nose, and Throat Hospital of Fudan University, 83 Fenyang Road, Shanghai 200031, People's Republic of China. ${ }^{2}$ Key Laboratory of Myopia, Ministry of Health, Shanghai 200031, People's Republic of China. ${ }^{3}$ Shanghai Key Laboratory of Visual Impairment and Restoration, Key NHC key Laboratory of Myopia, Fudan University, Shanghai 200031, People's Republic of China. ${ }^{4}$ Laboratory of Myopia, Chinese Academy of Medical Sciences, Shanghai 200031, People's Republic of China.

\section{Received: 12 July 2018 Accepted: 29 January 2019}

\section{Published online: 04 February 2019}

\section{References}

1. Carafa V, Miceli M, Altucci L, Nebbioso A. Histone deacetylase inhibitors: a patent review (2009 - 2011). Expert Opin Ther Pat. 2013;23(1):1-17.

2. Kuo MH, Allis CD. Roles of histone acetyltransferases and deacetylases in gene regulation. BioEssays. 1998;20(8):615-26.

3. de Ruijter AJ, van Gennip AH, Caron HN, Kemp S, van Kuilenburg AB. Histone deacetylases (HDACs): characterization of the classical HDAC family. Biochem J 2003; 370(Pt 3):737-749.

4. Behera J, Jayprakash V, Sinha BN. Histone deacetylase inhibitors: a review on class-I specific inhibition. Mini Rev Med Chem. 2015;15(9):731-50.

5. Ziemka-Nalecz M, Zalewska T. Neuroprotective effects of histone deacetylase inhibitors in brain ischemia. Acta Neurobiol Exp (Wars). 2014; 74(4):383-95.

6. Soragni E, Xu C, Cooper A, Plasterer HL, Rusche JR, Gottesfeld JM. Evaluation of histone deacetylase inhibitors as therapeutics for neurodegenerative diseases. Methods Mol Biol. 2011:793:495-508.

7. Marks PA. The clinical development of histone deacetylase inhibitors as targeted anticancer drugs. Expert Opin Investig Drugs. 2010;19(9):1049-66.

8. Dekker FJ, van den Bosch T, Martin NI. Small molecule inhibitors of histone acetyltransferases and deacetylases are potential drugs for inflammatory diseases. Drug Discov Today. 2014;19(5):654-60.
9. Rong X, Qiu X, Jiang Y, Li D, Xu J, Zhang Y, Lu Y. Effects of histone acetylation on superoxide dismutase 1 gene expression in the pathogenesis of senile cataract. Sci Rep. 2016;6:34704.

10. Wang $X, X u J$, Wang H, Wu L, Yuan W, Du J, Cai S. Trichostatin a, a histone deacetylase inhibitor, reverses epithelial-mesenchymal transition in colorectal cancer SW480 and prostate cancer PC3 cells. Biochem Biophys Res Commun. 2015;456(1):320-6.

11. Selin JZ, Lindblad BE, Rautiainen S, Michaëlsson K, Morgenstern R, Bottai M, Basu S, Wolk A. Are increased levels of systemic oxidative stress and inflammation associated with age-related cataract? Antioxid Redox Signal. 2014;21(5):700-4.

12. Varma SD, Kovtun S, Hegde KR. Role of ultraviolet irradiation and oxidative stress in cataract formation-medical prevention by nutritional antioxidants and metabolic agonists. Eye Contact Lens. 2011;37(4):233-45.

13. Wang Y, Li F, Zhang G, Kang L, Guan H. Ultraviolet-B induces ERCC6 repression in lens epithelium cells of age-related nuclear cataract through coordinated DNA hypermethylation and histone deacetylation. Clin Epigenetics. 2016;8:62

14. Li J, Liu R, Lei Y, Wang K, Lau QC, Xie N, Zhou S, Nie C, Chen L, Wei Y, Huang C. Proteomic analysis revealed association of aberrant ROS signaling with suberoylanilide hydroxamic acid-induced autophagy in Jurkat Tleukemia cells. Autophagy. 2010;6(6):711-24.

15. Qian J, Zhu W, Lu M, Ni B, Yang J. D- $\beta$-hydroxybutyrate promotes functional recovery and relieves pain hypersensitivity in mice with spinal cord injury. Br J Pharmacol. 2017;174(13):1961-71.

16. Wang X, Wu X, Liu Q, Kong G, Zhou J, Jiang J, Wu X, Huang Z, Su W, Zhu Q. Ketogenic metabolism inhibits histone deacetylase (HDAC) and reduces oxidative stress after spinal cord injury in rats. Neuroscience. 2017;366:36-43.

17. Wang Y, Chen T, Yan H, Qi H, Deng C, Ye T, Zhou S, Li FR. Role of histone deacetylase inhibitors in the aging of human umbilical cord mesenchymal stem cells. J Cell Biochem. 2013;114(10):2231-9.

18. Baltan S. Histone deacetylase inhibitors preserve function in aging axons. J Neurochem. 2012;123(Suppl 2):108-15.

19. Li B, Zhou J, Zhang G, Wang Y, Kang L, Wu J, Chen J, Guan H. Relationship between the altered expression and epigenetics of GSTM3 and age-related cataract. Invest Ophthalmol Vis Sci. 2016;57(11):4721-32.

20. Newman JC, Verdin E. Ketone bodies as signaling metabolites. Trends Endocrinol Metab. 2014;25(1):42-52.

21. Shimazu T, Hirschey MD, Newman J, He W, Shirakawa K, Le Moan N, Grueter CA, Lim H, Saunders LR, Stevens RD, Newgard CB, Farese RV Jr, de Cabo R, Ulrich S, Akassoglou K, Verdin E. Suppression of oxidative stress by $\beta$ hydroxybutyrate, an endogenous histone deacetylase inhibitor. Science. 2013;339(6116):211-4.

22. Newman JC, Verdin E. $\beta$-Hydroxybutyrate: much more than a metabolite. Diabetes Res Clin Pract. 2014;106(2):173-81.

23. Butler LM, Agus DB, Scher HI, Higgins B, Rose A, Cordon-Cardo C, Thaler HT, Rifkind RA, Marks PA, Richon VM. Suberoylanilide hydroxamic acid, an inhibitor of histone deacetylase, suppresses the growth of prostate cancer cells in vitro and in vivo. Cancer Res. 2000;60(18):5165-70.

24. Samuni Y, Flores-Santana W, Krishna MC, Mitchell JB, Wink DA. The inhibitors of histone deacetylase suberoylanilide hydroxamate and trichostatin a release nitric oxide upon oxidation. Free Radic Biol Med. 2009;47(4):419-23.

25. Samuni Y, Wink DA, Krishna MC, Mitchell JB, Goldstein S. Suberoylanilide hydroxamic acid radiosensitizes tumor hypoxic cells in vitro through the oxidation of nitroxyl to nitric oxide. Free Radic Biol Med. 2014;73:291-8.

26. Yoshida M, Kijima M, Akita M, Beppu T. Potent and specific inhibition of mammalian histone deacetylase both in vivo and in vitro by trichostatin a. J Biol Chem. 1990;265(28):17174-9.

27. Chen X, Xiao W, Chen W, Luo L, Ye S, Liu Y. The epigenetic modifier trichostatin a, a histone deacetylase inhibitor, suppresses proliferation and epithelialmesenchymal transition of lens epithelial cells. Cell Death Dis. 2013:4:e884.

28. Rosenberg G. The mechanisms of action of valproate in neuropsychiatric disorders: can we see the forest for the trees? Cell Mol Life Sci. 2007;64: 2090-103.

29. Zhao L, Chen C-N, Hajii N, Oliver E, Cotroneo E, Wharton J, Wang D, Li M, McKinsey TA, Stenmark KR, Wilkins MR. Histone deacetylation inhibition in pulmonary hypertension: therapeutic potential of valproic acid (VPA) and suberoylanilide hydroxamic acid (SAHA). Circulation. 2012;126(4):455-67.

30. Gottlicher M, Minucci S, Zhu P, Kramer OH, Schimpf A, Giavara S, Sleeman JP, Lo CF, Nervi C, Pelicci PG, Heinzel T. Valproic acid defines a novel class of HDAC inhibitors inducing differentiation of transformed cells. EMBO J. 2001; 20:6969-78. 
31. Duenas-Gonzalez A, Candelaria M, Perez-Plascencia C, Perez-Cardenas E. de IC$H$, Herrera LA. Valproic acid as epigenetic cancer drug: preclinical, clinical and transcriptional effects on solid tumors. Cancer Treat Rev. 2008;34:206-22.

32. Del Rio D, Stewart AJ, Pellegrini N. A review of recent studies on malondialdehyde as toxic molecule and biological marker of oxidative stress. Nutr Metab Cardiovasc Dis. 2005;15(4):316-28.

33. Sun L, Zang WJ, Wang H, Zhao M, Yu XJ, He X, Miao Y, Zhou J. Acetylcholine promotes ROS detoxification against hypoxia/reoxygenationinduced oxidative stress through FoxO3a/PGC-1a dependent superoxide dismutase. Cell Physiol Biochem. 2014;34(5):1614-25.

34. Brunet A, Sweeney LB, Sturgill JF, Chua KF, Greer PL, Lin Y, Tran H, Ross SE, Mostoslavsky R, Cohen HY, Hu LS, Cheng HL, Jedrychowski MP, Gygi SP, Sinclair DA, Alt FW, Greenberg ME. Stress-dependent regulation of FOXO transcription factors by the SIRT1 deacetylase. Science. 2004;303(5666):2011-5.

35. Song J, Guo D, Bi H. Chlorogenic acid attenuates hydrogen peroxideinduced oxidative stress in lens epithelial cells. Int J Mol Med. 2018;41(2): 765-72.

36. Zhu L, Zhao K, Lou D. Apoptosis factors of Lens epithelial cells responsible for Cataractogenesis in Vitrectomized eyes with silicone oil tamponade. Med Sci Monit. 2016;22:788-96

37. Ji Y, Rong X, Li D, Cai L, Rao J, Lu Y. Inhibition of cartilage acidic protein 1 reduces ultraviolet $\mathrm{B}$ irradiation induced-apoptosis through P38 mitogenactivated protein kinase and Jun amino-terminal kinase pathways. Cell Physiol Biochem. 2016;39(6):2275-86.

38. Fraczek J, Vanhaecke T, Rogiers V. Toxicological and metabolic considerations for histone deacetylase inhibitors. Expert Opin Drug Metab Toxicol. 2013;9(4):441-57.

39. Zheng Y, Chen H, Yin M, Ye X, Chen G, Zhou X, Yin L, Zhang C, Ding B. MiR$376 \mathrm{a}$ and histone deacetylation 9 form a regulatory circuitry in hepatocellular carcinoma. Cell Physiol Biochem. 2015;35(2):729-39.

40. Rotili D, Simonetti G, Savarino A, Palamara AT, Migliaccio AR, Mai A. Noncancer uses of histone deacetylase inhibitors: effects on infectious diseases and $\beta$-hemoglobinopathies. Curr Top Med Chem. 2009;9:272-91.

41. Jin JX, Lee S, Taweechaipaisankul A, Kim GA, Lee BC. The HDAC inhibitor LAQ824 enhances epigenetic reprogramming and in vitro development of porcine SCNT embryos. Cell Physiol Biochem. 2017;41(3):1255-66.

Ready to submit your research? Choose BMC and benefit from:

- fast, convenient online submission

- thorough peer review by experienced researchers in your field

- rapid publication on acceptance

- support for research data, including large and complex data types

- gold Open Access which fosters wider collaboration and increased citations

- maximum visibility for your research: over $100 \mathrm{M}$ website views per year

At $\mathrm{BMC}$, research is always in progress.

Learn more biomedcentral.com/submissions 